Recife, Volume 9, 2020 (14-19)

https://doi.org/10.46802/rmsde.v9i2.248608

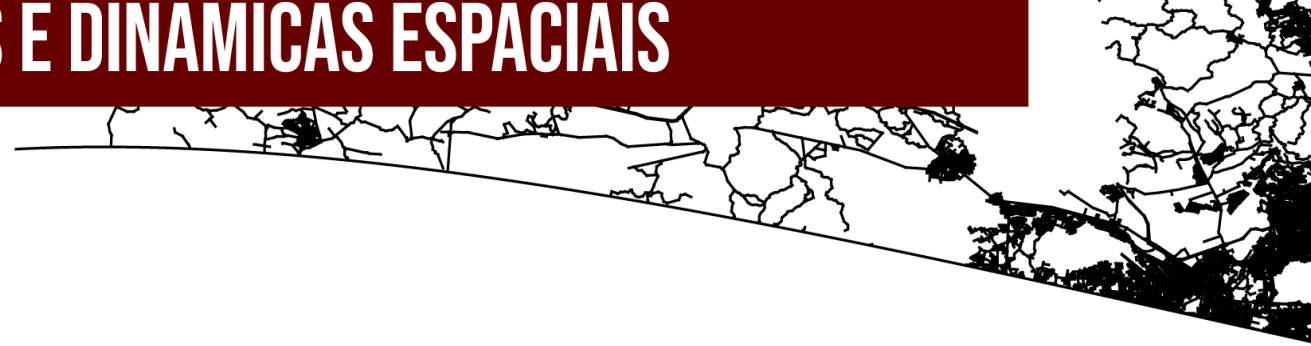

\title{
“DOSSIÊ COVID-19"
}

\section{A POLIITICA DA PANDEMIA DO COVID-19 NA EUROPA: REFLEXÕES SOBRE MEDIDAS DE CONTENÇÃO E OS IMPACTOS NA SOCIEDADE}

\author{
COVID-19 PANDEMIC POLICY IN EUROPE: \\ REFLECTIONS ON CONTAINMENT MEASURES AND IMPACTS ON SOCIETY
}

Ronaldo CAMPOS 1

Artigo recebido em 18/10/2020, aceito em 17/11/2020, publicado em 18/12/2020.

\section{Palavras-chave: \\ Política \\ Internacional; \\ Pandemia; \\ Democracia; \\ Europa.}

Keywords:

International

Politics; Pandemic;

Democracy;

Europe.

\section{RESUMO}

A pesquisa apresenta estudos sobre a política da pandemia do Covid-19 na Europa. Movimentos políticos contra e a favor orientações da Organização Mundial de Saúde (OMS) para contenção da pandemia encontram-se no cenário europeu e disputam espaços de poder em plena expansão da pandemia. Ameaças à democracia europeia e ao sistema democrático surgem nesse contexto impactando os ecosistemas da vida no planeta, do político ao comportamental na sociedade. A análise aborda na perspectiva teórica o debate sobre política internacional a partir da discussão dos efeitos da pandemia do Covid-19 no sistema democrático. Os resultados apontam pressões políticas nos países da União Europeia (UE) e no sistema democrático, alvo de transformações nas relações internacionais.

\section{ABSTRACT}

The research presents studies on the Covid-19 pandemic policy in Europe. Political movements against and in favor of the guidelines of the World Health Organization (WHO) to contain the pandemic are found in the European scenario and dispute spaces of power in full expansion of the pandemic. Threats to European democracy and the democratic system arise in this context, impacting the ecosystems of life on the planet, from the political to the behavioral in society. The analysis approaches in the theoretical perspective the debate on international politics from the discussion of the effects of the Covid-19 pandemic on the democratic system. The results point to political pressures in the countries of the European Union (EU) and in the democratic system, the target of changes in international relations.

\footnotetext{
1 Professor de Ciência Política do Bacharelado em Ciências Sociais e do Programa de Pós-graduação em Gestão de Políticas Públicas GESPOL da Universidade Federal do Tocantins - UFT. Pesquisador do Grupo de Pesquisa Sociedade e Natureza - NEXUS / UFPE e do Grupo de Pesquisa Regularização Fundiária Urbano e Rural no Estado de Pernambuco - RFURPE / UFPE. Pesquisador do Zentrum Technik und Gesellschaft - ZTG da Technische Universität Berlin - TU Berlin. E-mail: camposbr@hotmail.com.
} 


\section{INTRODUÇÃO}

Os estudos sobre política internacional e sistema democrático exigem uma compreensão sistêmica da dinâmica do poder político. A pandemia do Covid-19 tornou-se uma variante nessa competição com movimentos políticos nas sociedades ocidentais contra ou a favor orientações da Organização Mundial de Saúde (OMS). Esses movimentos surgem como ameaças à democracia europeia e ao sistema democrático e as orientações da OMS alertam sobre devastação da pandemia apontando impactos nos ecossistemas.

O problema investigado exige debates transversais sobre os impactos do Covid-19 nas sociedades e nas políticas dos estados nacionais europeus. Observa-se na literatura contemporânea discussões sobre efeitos da pandemia no sistema democrático. O método de investigação busca a sistematização do conhecimento, exploratório e bibliográfico, além de documental-científico com base nos estudos sobre a compreensão das pressões políticas nos países da União Europeia (UE) e no sistema democrático a partir dos impactos do Covid-19.

Desta forma, a situação pandêmica requer da política novos diálogos e reflexões sociológicas do contexto político. Constata-se que a atual pandemia mantém a política sob pressão, além de ameaçar vidas humanas em escala global e numa dinâmica espacial sem limites. Expondo risco aos objetivos principais das democracias liberais: o bem-estar de seus cidadãos e a proteção da vida humana que formam a base da liberdade individual e das oportunidades de desenvolvimento. A escala do desafio se reflete na natureza radical das políticas destinadas à contenção da pandemia. Em estados democráticos, as liberdades individuais foram suspensas e impostas restrições em todas as áreas da sociedade e na vida privada dos cidadãos.

Os debates giram em torno de argumentos baseados na observação no interior das sociedades e procedimentos democráticos na formulação de políticas pandêmicas. 0 presente artigo observa medidas institucionais para compreender a interrelação entre política e sociedade. Como exemplo, a crise política da UE como instituição e os países membros, demonstram que um estado democrático é capaz de lutar com sucesso contra uma pandemia, porém a democracia liberal tropeça em seus próprios princípios em vários aspectos. Desta forma, a relevância do trabalho está na compreensão dos obstáculos democráticos que se tornam visíveis no curso da política pandêmica, sendo um passo importante para defender democracias na luta contra problemas semelhantes. 


\section{MÉTODO}

A metodologia busca o conhecimento sistematizado, levantamento bibliográfico e documental, acerca dos estudos sobre política internacional e o sistema democrático como pano de fundo da investigação. A pesquisa é parte de estudos que exploram temáticas relacionadas em projetos de pesquisa que envolvem debates críticos sobre relações políticas, econômicas, ambientais e sociais a partir do conhecimento científico. Este estudo pretende preencher lacunas, interagir temáticas e observar, neste momento, os efeitos pandêmicos do Covid-19 à luz da conjuntura política e social, no cenário europeu e com vista na possível ameaça à democracia europeia e ao sistema democrático.

A base para tratar o objeto de investigação é a análise política da pandemia do Covid-19 e os efeitos que levam à transformação do sistema democrático. Desta forma, o estudo procurou refletir sobre medidas de contenção do Covid-19 e os impactos na sociedade com base nos conteúdos teóricos críticos e estudos analítico-científicos como método à investigação. O levantamento teórico proporcionou a construção analítica sobre o processo pandêmico instaurado na sociedade, as políticas da pandemia do Covid-19 na Europa e as instituições na interrelação entre política e sociedade. Os exemplos da política europeia e da crise dos estados nacionais durante a pandemia atual, são sem dúvida diálogos entre o estado democrático que demonstra ser capaz de avançar na situação pandêmica e na condução dos problemas eminentes da democracia liberal e a compreensão dos empecilhos que afrontam o conjunto das democracias.

\section{RESULTADOS E DISCUSSÃO}

Em resposta aos primeiros casos do coronavírus nas cidades europeias entre fevereiro e março de 2020 (Mello-Théry \& Théry, 2020, p. 2-3) ou à percepção de que a disseminação em larga escala do Covid-19 era um cenário provável em países da Europa, a política dos estados nacionais nos primeiros momentos parecia onipresente (Hänsel, 2020). Logo foram tomadas decisões políticas com efeito coletivo, interferiram na vida cotidiana individual e paralisaram a vida pública. Desse modo, os governos dos países da UE proibiram os contatos, decidiram sobre quarentenas, limitaram as liberdades individuais e as oportunidades de participação na sociedade segundo o critério de relevância sistêmica (Vasconcellos, 2010; Dowbor, 2020).

Essas decisões foram tomadas por instituições e governos democraticamente legitimados e seguiram recomendações dos ministérios e institutos de política sanitária, infectologistas, entre outros. A eficácia das máscaras, a duração das proibições de contato, a necessidade de vigilância digital e as informações científicas dos institutos de pesquisa e dos especialistas foram as principais medidas de contenção que 
inseriram os representantes da política e suas decisões sob pressão. A mídia, redes sociais e plataformas digitais divulgaram essas medidas obtendo um efeito formal na sociedade, ignorar ou transgredir tornou-se impensável.

Diante da situação avassaladora do problema de saúde pública, as instituições democráticas seguiram especialistas e organizações científicas em sintonia com orientações da OMS (United Nations, 2020, p. 1). A maior parte das decisões políticas foram tomadas com aprovação do público e da política consensual. Os acordos entre governo e oposição marcaram a política pandêmica nos países da UE e esses acordos foram livres de conflitos, levando à sociedade um efeito tranquilizador da imagem pública, considerando que não existem soluções alternativas racionais diante da ameaça representada pelo Covid-19 num contexto global (United Nations, 2020, p. 23-24).

Na verdade, não se pode afirmar que houve um desempenho democrático, no significado da socialdemocracia europeia, por parte dos estados nacionais. Em vez disso, independente dos efeitos positivos ou sucessos dos governos, representa uma ação política democrática, cujo significado está no debate sobre opções de ação de bem comum. A política é o confronto permanente entre os adversários, o espaço de posições divergentes em relação ao comum. Para a filósofa Hannah Arendt, pensamento político significa considerar uma infinidade de perspectivas, entre as quais uma seja determinada como dominante (Arendt, 2020, p. 201-203). O sentido político desaparece assim que o pluralismo se transforma em homogeneidade por meio de critérios universais de razão e as decisões como finais, restando regras coletivas da política internacional (Hänsel, 2020, p. 3-4).

É certo afirmar que a forma ideal de debate político nem sempre ocorre nas democracias modernas. Na medida em que a política moderna é julgada por eficiência e disponibilidade de soluções aos problemas sociais e conhecimento científico. Existem campos de ação nas operações democráticas onde a opinião externa dos especialistas dominam e a política se limita. Nas democracias, entretanto, a terceirização de competências sempre ocorre sob a condição de responsabilidade e tomada de decisão e os limites são monitorados, segundo Kotz (2018), no formado da realpolitik.

As atividades na sociedade retornaram no final de abril de 2020 nos estados nacionais da UE (MelloThéry \& Théry, 2020), com relaxamento das restrições de saída, obrigação de máscaras, retomada das atividades escolares e abertura de serviços e comércios. Embora os primeiros passos fossem acompanhados por indicadores dos governos e alertas de imprudência e otimismo, os especialistas em saúde pública e representantes políticos apareceram nos meios de comunicação por semanas opinando sobre a situação pandêmica, os conflitos foram resolvidos e as medidas políticas amparadas pelos especialistas.

Por um lado, o contraste entre a política de flexibilização e o bloqueio tornou-se evidente, de outro, revela-se um paralelo entre modo de permissão à sociedade e exclusão da liberdade individual a partir da 
posição política (Arendt, 2020). O trato com a pandemia e o risco não está mais sujeito à experiência do sistema funcional, portanto, a gestão de risco depende do comportamento e das decisões individuais dos cidadãos, onde cada indivíduo é responsabilizado pelo objetivo comum e igualmente pelo sucesso ou fracasso (Zelik, 2020). Nesta conjuntura, a orientação quantitativa entre infecção e transmissão marca o limite da individualização, fato discutido desde meados de outubro 2020 com a segunda onda do Covid-19.

A população europeia e dos demais países afetados pela pandemia iniciaram o isolamento social no período de bloqueio, durante a primavera na Europa ou nos primeiros meses de 2020, quando as regras de higiene mais rígidas se tornaram parte do cotidiano a maioria da população ficava em casa mesmo sem um toque de recolher formal e todos passaram a se encorajar mutuamente e perseverar uns aos outros. Observase que além da estrutura das instituições estatais e dos processos de tomada de decisão, a política em seu contexto social não acontece sem conflito (Arendt, 2020).

Esse conflito não resulta do óbvio, como a restrição das liberdades civis nas sociedades em geral, mesmo quando isso acontece, requer a vigilância sanitária diante da pandemia. Contudo, é certo afirmar que conflitos com a sociedade surgem do fato da política pandêmica está baseada em condições e produz efeitos contrários à essência da democracia liberal. De modo que, a democracia acaba tropeçando em seus próprios princípios e isso pode ser ilustrado a partir da privacidade como virtude cívica, denúncia como solidariedade e dissidência democrática (Alves, 2019; United Nations, 2020; Arendt, 2020).

A privacidade como virtude cívica (Alves, 2019) na situação pandêmica é parte do comportamento individual na sociedade, mas influenciado pela política. O privado, enfatizou Hannah Arendt, é caracterizado pela ausência de outros e pela desigualdade interna dos membros de uma sociedade (Arendt, 2020, p. 219222). Estar no privado implica a inexistência como pessoa pública e política, portanto, a exclusão da participação na formação do bem comum (Zelik, 2020). A denúncia como solidariedade torna-se um ato político para o bem comum, solidariedade com os outros, com os grupos de risco e aqueles na vanguarda do combate ao Covid-19 (United Nations, 2020) e é um conceito-chave na abordagem ao público.

A dissidência democrática no contexto da posição individual remete-se não apenas ao cotidiano, sanções e padrões de exclusão se estabelecem com medidas políticas do Covid-19 contra comportamentos fora das expectativas. As decisões coletivas basearam-se na realidade e a política se priva de confrontar os críticos ou aqueles que representam posições diferentes, segundo Kotz, surge assim a dimensão da realpolitik (Kotz, 2018, p. 51). Todavia, protestos surgiram como aglomeração de populistas de direita e teóricos da conspiração, que consideram a pandemia um instrumento do governo, alertando contra uma ditadura da saúde. Devido à restrição abrangente ao político, segundo Hannah Arendt, limita assim possibilidades de reflexão e ação (2020, p. 222-223). A pandemia do Covid-19 transformou-se numa 
competição global do sistema de poder (Hänsel, 2020) influenciando relações nas áreas de comércio, política externa e divulgação midiática (Boomgaarden, 2020; Boone, 2020).

\section{REFERÊNCIAS}

Alves, V. F. C. (2019). Rousseau e a virtude cívica na república. Revista doispontos:, 16(1), 71-84.

Arendt, H. (2020). Freiheit und Politik. In: H. Arendt, Zwischen Vergangenheit und Zukunft. U. Ludz (Hg.), $6^{a}$ Aufl. München, 201-226.

Boomgaarden, G. (2020). 12 Perspectives on the Pandemic. International social science thought leaders reflect on Covid-19. Disponível:

https://www.degruyter.com/fileasset/craft/media/doc/DG _12perspectives_socialsciences.pdf

Boone, L. (2020). Tackling the fallout from COVID-19. In: B. Weder Di Mauro \& R. Baldwin (Eds.), Economics in the Time of Covid-19, London: CEPR Press, 37-44.

Castells, M. (1996). The Rise of the Network Society. Oxford: Malden.

Dowbor, L. (2020). Além da Pandemia: uma convergência de crises. In: J. D. Passos (Org.), A Pandemia do Coronavírus: Onde estivemos? Para onde vamos? São Paulo: Paulinas, 25-48.

Ferdinand, P. (2016). Westward ho - the China dream and 'one belt, one road': Chinese foreign policy under Xi Jinping. International Affairs, 92(4), 941-957.

Mello-Théry, N. A. de \& Théry, H. (2020). A geopolítica do COVID-19. Espaço e Economia: Revista brasileira de geografia econômica. UERJ/UFRRJ, Rio de Janeiro, (17), p. 1-9. doi.org/10.4000/escoeconomia.11224

Hänsel, L. (2020). Systemic Challenge: Geopolitics in Times of Corona. Disponível:
https://www.kas.de/documents/252038/7995358/Syste mic+Challenge+-+Geopolitics+in+Times+of+Corona.pdf

Kotz, R. L. (2018). A Nova Rota da Seda: entre a tradição histórica e o projeto geoestratégico para 0 futuro. Florianópolis: UFSC.

Majerowicz, E.; Medeiros, C. A. de. (2018). Chinese Industrial Policy in the Geopolitics of the Information Age: the case of semiconductors. Revista de Economia Contemporânea, 22(1), 1-28.

Stuenkel, O. (2018). O mundo pós-ocidental: Potências emergentes e a nova ordem global. Rio de Janeiro:

Zahar.

United Nations. (2020). Gemeinsame Verantwortung, Globale Solidarität: Bewältigung der sozioökonomischen Auswirkungen von COVID-19. Disponível:

https://www.un.org/Depts/german/gs/COVID19_shared_responsibility_global_solidarity_reportDEU.pdf

Vasconcellos, M. J. E. de. (2010). Pensamento sistêmico: O novo paradigma da ciência ( $\left(9^{\mathrm{a}} \mathrm{ed}\right.$.). Campinas: Papirus.

Zelik, R. (2020). In Verteidigung des Lebens Über die Corona-Pandemie, die sozialökologische Großkrise und die Möglichkeit eines neuen Sozialismusbegriffs. PROKLA, 50(2), 345-353. 